\title{
ILLNESS PERCEPTION, MOTIVATION, AND SELF-CARE BEHAVIOR IN DIABETIC PATIENTS
}

\author{
Tjahja Bintoro'), Made Mahaguna Putra'²), Ni Made Dwi Yunica Astriani²), \\ Putu Indah Sintya Dewi²) \\ ${ }^{1)}$ Graduate School, Universitas Sebelas Maret \\ ${ }^{2)}$ School of Health Sciences, Buleleng, Bali
}

\begin{abstract}
Background: Diabetes mellitus (DM) is a chronic progressive metabolic disorder characterized by hyperglycemia mainly due to absolute or relative deficiency of insulin hormone. Evidence suggests that lifestyle and other non-pharmacological interventions can delay and even prevent the development of type $2 \mathrm{DM}$ and its complications. However, to date, studies into factors associated with preventive health behavior among patients with type 2 DM have been lacking. This study aimed to determine the association between illness perception, motivation, and self-care behavior in diabetic patients.

Subjects and Method: This was a cross-sectional study. A total of 177 diabetic patients was selected for this study using stratified random sampling. The dependent variable was self-care behavior, consisting of: diet, physical exercise, blood sugar screening, treatment compliance, and foot care. The independent variables were illness perception and motivation. The data were collected using questionnaire and analyzed using multiple hierarchical regression.

Results: Illness perception was related to self-care behavior including $43.2 \%$ variance in diet, $11.4 \%$ variance in physical exercise, 9.1\% variance in blood sugar screening, $\mathbf{1 1 . 7 \%}$ variance in treatment compliance, and $10.1 \%$ variance in foot care, and they were statistically significant. Motivation was related to self-care behavior including $0.04 \%$ variance in physical exercise, $0.08 \%$ variance in blood sugar screening, and $0.04 \%$ variance in treatment compliance, and they were statistically significant.

Conclusion: Illness perception and motivation are related to self-care in patients with type 2 diabetes mellitus.

Keywords: illness perception, motivation, self-care behavior, diabetes mellitus

Correspondence:

Tjahja Bintoro; Made Mahaguna Putra. Graduate School, Universitas Sebelas Maret, Surakarta, Central Java; School of Health Sciences, Buleleng, Bali. Email: btjahja34@yahoo.co.id.

Mobile: 081330758511; Email: md.mahagunaputra@gmail.com. Mobile: o81330758511
\end{abstract}

The $5^{\text {th }}$ International Conference on Public Health

Best Western Premier Hotel, Solo, Indonesia, February 13-14, 2019 | 236

https://doi.org/10.26911/theicph.2019.02.46 